\title{
Treatment of chronic pain by spinal cord stimulation
}

\author{
F. Aichaoui ${ }^{1}$, A. Khelifa ${ }^{1}$, I. Assoumane ${ }^{2}$, \\ M. Al-Zekri' ${ }^{1}$ A. Morsli ${ }^{1}$ \\ 1 Neurosurgical Department of BEO University Hospital, Algiers, \\ ALGERIA \\ 2 National Hospital of Niamey, NIGER
}

\begin{abstract}
Failed back surgery syndrome (FBSS) is often used to describe the condition of patients who have experienced continued pain after surgery. It is of multifactorial genesis and may be the consequence of various lumbar spinal diseases; lumbar disc herniation surgery or spinal canal stenosis laminectomy. The presented series included 13 patients affected with chronic pain related to FBSS who underwent implantation of spinal cord stimulation. The mean percentage of pain relief was $90 \%$ for all patients. $60 \%$ of the patients were in a better psychological status and the intake of analgesic medications has been reduced of more than $70 \%$. More than $50 \%$ of the patients could resume professional activities. Analysis of the risks and benefits comes in favour of spinal cord stimulation.
\end{abstract}

\section{INTRODUCTION}

Chronic pain can be seen in 12 to $40 \%$ of patients that underwent a spine surgery according to the series $(13,14)$. This persistent pain is known as Failed Back Surgery Syndrome (FBSS) (8). Clinically it appears in the form of lumbar and / or radicular pain. This Pain syndrome often appears after multiple surgical procedures for disc herniation or stenotic spinal canal. It can usually be explained by the contribution of several factors including arachnoiditis or periradicular fibrosis (15). The patients have mixed pain syndrome of neuropathic and nociceptive character; the neuropathic component is found in 80 to $96 \%$ for lumbosciatic and 8 to $16 \%$ for lumbago (5). The FBSS is one of the indications of the spinal cord stimulation after failure of conservative treatment (13). This neurostimulation performed for the first time by Shealy et al in 1967, consists of placing electrodes in the epidural space in contact with the spinal cord. According to the series, this technique can improve this pain syndrome in 55 to $88 \%$ of cases (2).

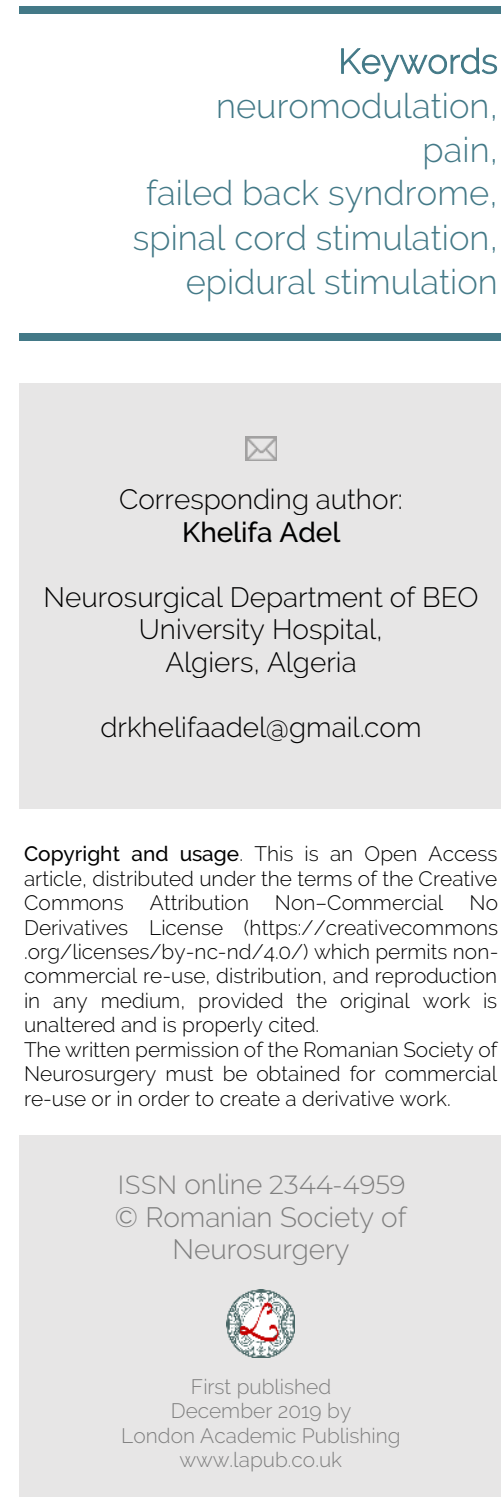




\section{MATERIALS AND METHODS:}

\section{Patient's selection}

We performed a prospective a study of 13 patients with a spinal cord stimulator for persistent chronic pain after spinal surgery. This work was held from May 2013 to December 2017. Our serie includes 6 women and 7 men with an average age of 42 years with extreme ages of 21 and 66 years. All patients had a detailed clinical evaluation including their pain characteristics, the intensity of the pain using the Visual Analogue Scale (VAS), the drugs intake using MQS (Medication Quantification Scale), and an assessment of the psychological impact of the pain (Table 1). Imaging investigations and electrophysiology were performed before spinal cord stimulation. Imaging, represented by $\mathrm{CT}$ and / or spinal MRI, eliminated the presence of disc herniations or stenotic spinal canal. Implantation concerned patients with severe pain (VAS> 5/10), chronic pain (> 6 months) and resistant pain to usual treatment.

\section{Etiologies}

The chronic pain that affected our patients was due to herniated disk surgery in 11 cases $(84.6 \%)$, of narrow lumbar canal surgery in one case $(7.7 \%)$ of scoliosis surgery also in one case (7.7\%). Patients who had been implanted for post-traumatic spine pain or for any other condition were excluded from the study (Table 1).

\section{Characteristics of the pain}

Patients suffered from radiculalgia of the lower limbs with or without chronic low back pain. They were of neuropathic type (> 4 at the DN4 score), evolving for more than six months, resisting to several categories of treatments including opioids, anticonvulsants, and tricyclic antidepressants. Four patients had previously benefited from transcutaneous stimulation that did not cover the entire pain territory. The delay between the onset of pain and implantation of the spinal cord stimulator was average of 8 years with an interval between 2 and 24 years.

\section{Implant procedure}

We use wide and flat electrodes with 16 contacts (PENTA, Saint Jude ${ }^{\circledR}$ ). Their plate configuration allows them to be in contact with the dura over a large area and to generate a $180^{\circ}$ stimulation field in the direction of the spinal cord. These types of electrodes are designed to reduce energy consummation by minimizing losses. The wide conformation of the electrode requires an open surgical approach for better visual control of the epidural space. The procedure is performed under general anesthesia in the prone or right lateral position. After minimal skin incision and dissection of the musculo-fascial planes, the electrode is introduced through an inter-spinous approach to have a bilateral effect, at the T9-T10 space (Figure.1). A radiological check is performed to confirm the correct positioning (Figure.2). Then, the wires of this electrode are tunneled to the left subcostal or left subclavian level. A short incision is made at this point to implant the generator after having connected it to the wires of the electrode.

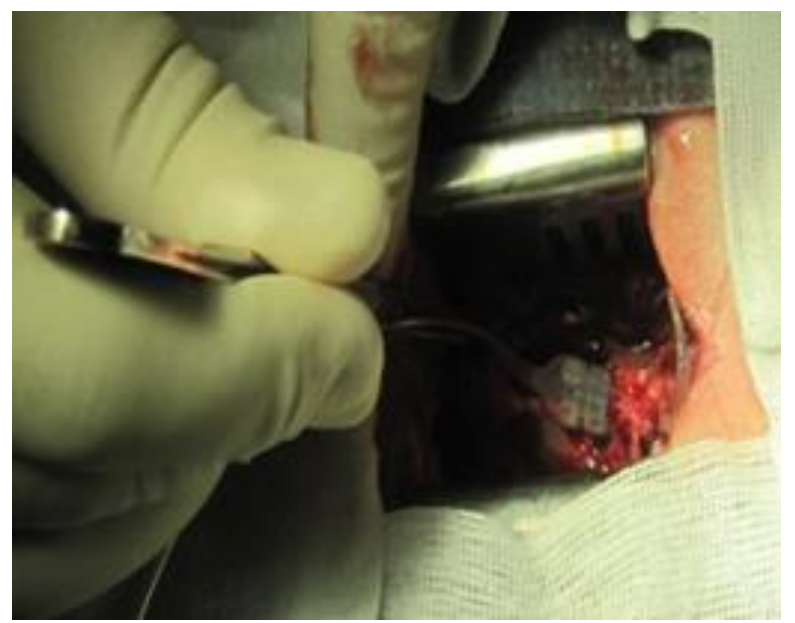

Figure 1: The electrode is introduced into the Epidural space in contact with the spinal cord.

Figure 2: Control X-ray for the good position of the electrode.

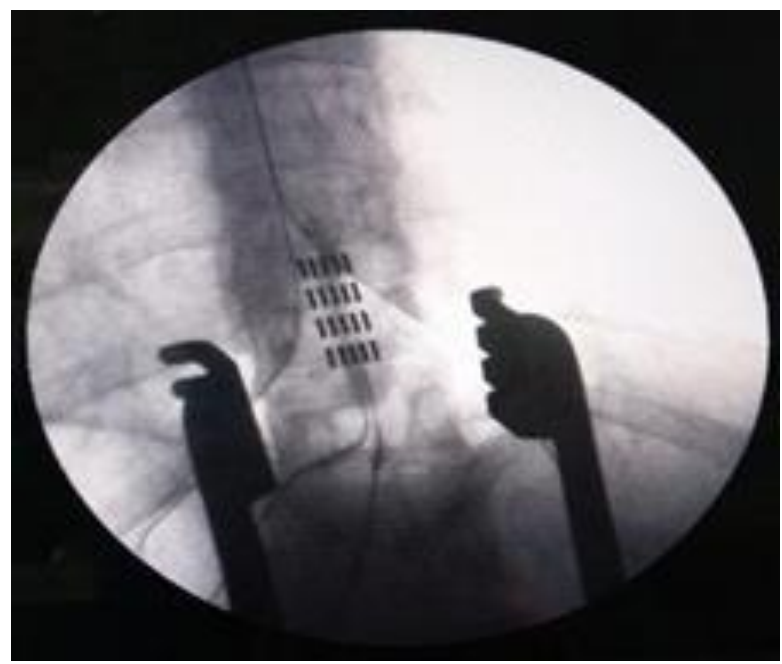




\section{RESULTS}

The stimulator is started the day after surgery. The parameters used are variable according to the patients with 200 microseconds on average (between 50 and $500 \mu \mathrm{sec}$ ), a frequency of $30 \mathrm{~Hz}$ (between 30 and $400 \mathrm{~Hz}$ ) and amplitude of $6 \mathrm{~mA}$ (between 2 and $20 \mathrm{~mA}$ ). The settings are refined between 1 and 3 months. The long-term evaluation was performed at 6 months for five patients, at one year for three patients and beyond two years for five patients. The average duration of follow-up is 20 months. All patients reported a relief of more than $50 \%$ of the pain intensity at the end of the first settings of the stimulation. Statistical analysis showed a significant improvement. The improvement is estimated at $90 \%$ with a VAS that went from 8.8 to 0.8 . The consumption of analgesics has been reduced by $71.8 \%$. This reduction goes hand in hand with improving the quality of life of patients in more than $60 \%$ of cases. The professional reintegration concerned more than half of the patients in activity with an arranged post in $60 \%$ of the cases. The surgical technique was not accompanied by serious complications. We noted a pain of the surgical site resolving under analgesic, a case of dura tear repaired in per operative and a case of hematoma development around the generator requiring drainage.

\begin{tabular}{|c|c|c|c|c|c|c|c|c|c|}
\hline Patients & Sex & Age & Surgery & Locations & $\begin{array}{c}\text { Initial } \\
\text { VAS }\end{array}$ & $\begin{array}{c}\text { Initial } \\
\text { MQS }\end{array}$ & $\begin{array}{c}\text { Lower } \\
\text { opioids }\end{array}$ & $\begin{array}{c}\text { Higher } \\
\text { opioids }\end{array}$ & $\begin{array}{c}\text { Follow-up } \\
\text { (months) }\end{array}$ \\
\hline 1 & M & 21 & Dis & Dif, LL, Bil & 8.5 & 32 & YES & NO & 54 \\
\hline 2 & F & 37 & Dis & Dif, LL, Bil & 9.5 & 32 & NO & YES & 34 \\
\hline 3 & F & 40 & Dis & LS, Uni & 9.5 & 32 & YES & NO & 31 \\
\hline 4 & M & 47 & Dis+Lam & Dif, LL, Bil & 8.5 & 32 & YES & NO & 26 \\
\hline 5 & M & 52 & Lam & Dif, LL, Bil & 8 & 32 & YES & NO & 26 \\
\hline 6 & M & 66 & Dis+Lam & Dif, LL, Bil & 9.5 & 32 & YES & NO & 20 \\
\hline 7 & F & 34 & Dis+Lam & LS, Uni & 10 & 32 & YES & NO & 19 \\
\hline 8 & M & 41 & Scol & Dif, LL, Uni & 10 & 27 & NO & NO & 14 \\
\hline 9 & F & 49 & Dis+Lam & LS, Uni & 7 & 18 & YES & NO & 9 \\
\hline 10 & M & 47 & Dis+Lam & GU & 8.5 & 30 & YES & NO & 8 \\
\hline 11 & M & 47 & Dis+Lam & LS, Bil & 8.5 & 23 & NO & NO & 8 \\
\hline 12 & F & 63 & Dis+Lam & Dif, LL, Bil & 8.5 & 24 & NO & NO & 8 \\
\hline 13 & F & 48 & Dis+Lam & Dif, LL, Bil & 8.5 & 7 & NO & NO & 6 \\
\hline
\end{tabular}

Table 1: summery of the preoperative data and the follow up duration for each patient. Dif : diffuse, LS : lombosciatalgia, GU : Genitourinary, LL : lower limb, Bil : bilateral, Uni : unilateral, Dis : discectomy, Lam : laminectomy, Scol : scoliosis correction rods removal, VAS (Visual Analogue Scale), MQS (Medication Quantification Scale).

\section{DISCUSSION}

Persistent pain after spinal surgery or "FBSS" is the result of several factors including major and / or prolonged compression of the nerve root during the preoperative period, the occurrence of a surgical complication or nerve damage in peroperative $(14,23)$. The occurrence of arachnoiditis or periradicular fibrosis is a major contributor to pain $(10,14)$, and infection can lead to chronic pain after the appearance of a epidural compressive fibril tissue (23). All our patients presented, prior to implantation of the spinal cord stimulator, a radicular pain at the electromyogram (EMG) with scar tissue on the operative site on imaging but without recurrence of herniated disk or residual stenotic spinal canal. The patients suffered from pains of the two lower limbs mainly in lombosciatalgia often extended without precise territory. These pains had a neuropathic character with a DN4 score greater than 4 , it is in this context that the indication of spinal cord stimulation was retained. The indication of spinal cord stimulation in neuropathic pain, especially in the "FBSS", is widely accepted (4). The control of pain by spinal cord stimulation is based on gate control theory developed by Melzack and Wall in 1965 (16), in fact, reinforcing the large diameter $A \beta$ fibers, increases the inhibitory system of interneurons in lamina II of the dorsal horn of the spinal cord on the transmission of ascending pain. We implanted our patients with 16 contact electrodes (PENTA, Saint Jude $\left.{ }^{\circledR}\right)$ surgically. The open-air implantation allows a 
better visual control of the epidural space. The wide configuration of the electrodes makes it possible a large contact with the convexity of the dura (19).The use of 16-contact electrodes allows a multitude of programming combinations (11). This is interesting in cases of pain with a territory that is very extensive or difficult to recruit (12). The collection of the different evaluation criteria highlights a significant gain on the MQS (Medication Quantification Scale) and VAS (Visual Analogue Scale) (16). Drug use is reduced by $42.7 \%$ at 3 months and by $71.8 \%$ at more than 6 months with suppression of opioids. In fact, the mean value of the initial MQS (preoperative) was $27.15 \pm 7.58$ (95\% Cl: 22.57-31.74); passed to $15.54 \pm$ 8.08 (95\% Cl: 10.66-20.42) at 3-month, and to $8 \pm 8.90$ (95\% Cl: 2.62-13.38) at more than 6 months (Figure $3)$. The drug reduction has been planned and progressive. It was accompanied by fewer side effects and an improvement in the quality of life. The effectiveness of spinal cord stimulation is defined as obtaining a relief of at least $50 \%$ of the intensity of neuropathic pain (14). In the literature, the results of spinal cord stimulation vary, depending on the series, between $47 \%$ and $88 \%(3,6,14)$. For our part, we obtained a regression of $90 \%$ of the pain. The average preoperative VAS was $8.81 \pm 0.85$ ( $95 \% \mathrm{Cl}$ : 8.29-9.32). Average postoperative VAS at 3 months increased from $3 \pm 1.08$ (95\% Cl: 2.35-3.65) to $0.88 \pm$ 1.04 (95\% Cl: 0.25-1.52) at more than 6 months (Figure. 3). The average duration of follow-up is 20 months with an interval between 6 and 54 months. The gradual improvement of VAS beyond the first three months is linked to the optimization of stimulation parameters during successive consultations. Patients reported walking facilitation due to improved proprioceptive conduction (1). All this has allowed half of the patients in working age to return to work with an arranged post in $60 \%$ of them. These results of spinal cord stimulation in the FBSS show a significant gain on both the pain and its repercussions. Moreover, the lack of response to the transcutaneous stimulation in the preoperative phase in our patients is not a negative value of spinal cord stimulation. The delay between the onset of pain and implantation of the pacemaker is 8 years on average. This delay is considered relatively long, but it has not acted negatively on the outcome of the results. In the literature, the factors predicting the efficacy of spinal cord stimulation are dependent on several elements, in particular, the neuropathic pain that evolves in uni or bilateral radicular mode (6), and the delay exceeding 3 years after the first surgical intervention. $(13,14)$. The low rate of complications encountered in this series corroborates the results of the literature (11). The phenomenon of tolerance or habituation, synonymous with exacerbation of pain over time, has not been observed in our patients. This phenomenon is not frequently cited by the authors (9). However, it can be overcome by an adaptation of the stimulation parameters. The longterm socio-economic impact is in favor of spinal cord stimulation if we take into account the relief of pain, the reduction or even the stopping of medications and the possibility of reintegration in work (7).

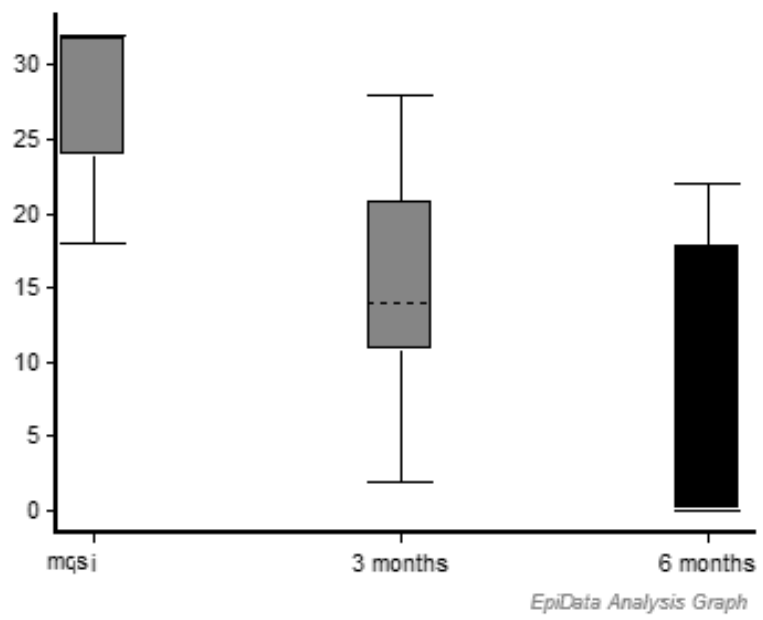

Figure 3: Evolution of the MQS (Medication Quantification Scale): preoperative (mqsi) and postoperative (at 3months and $>6$ months).

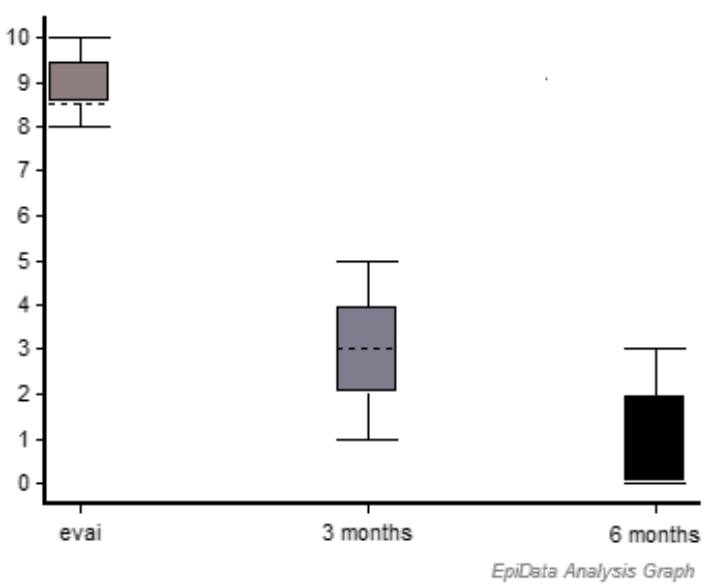

Figure 4: Evolution of the VAS (Visual Analogue Scale): preoperative (VASi) and postoperative (at 3months and> 6months). 


\section{CONCLUSION}

The benefit / risk ratio is largely in favor of spinal cord stimulation in the management of patients with FBSS. The indication is dependent on a good selection of patients. Finally, spinal cord stimulation must be part of the therapeutic arsenal of the FBSS.

\section{Declarations of interest:}

None.

\section{Funding:}

This research did not receive any specific grant from funding agencies in the public, commercial, or not-for-profit sectors. References:

\section{REFERENCES}

1. Hatzis, G. Stranjalis, C. Megapanos, P. G. Sdrolias, I. G. Panourias, and D. E. Sakas. The current range of neuromodulatory devices and related technologies. Acta Neurochir Suppl (2007) 97(1): 21-29

2. M. Raslan, S. McCartney, and K. J. Burchiel. Management of chronic severe pain: spinal neuromodulatory and neuroablative approaches. Acta Neurochir Suppl (2007) 97(1): 33-41

3. Abeloos L, De Witte O, Riquet R, et al. (2011) [Long6terme outcome of patient treated with spinal cord stimulation for therapeutically refractory failed back surgery syndrome : a retrospective study ], Neuro-Chirurgie 57 (3) : 114-119

4. Assaf G, Sheng Z, Yong K, Gharibo C (2007) Challenges to sitting Spinal Cord Stimulator Parameters During Intraoperative Testing Factors Affecting Càverage of Law back and Leg pain. Neuromodulation : Tzchnolgy of the Neural Interface 10(2)

5. Attal N, Perrot S, Fermanian J, Bouhassira D (2011) The neuropathic components of chronic low back pain : a prospective multicenter study using the DN4 Questionnaire.J Pain off LAm Pain Soc 12 : 1080-1087

6. Barolat G, OaKley JC, Law JD, et al. (2001) Epidual spinal cord stimulation with a multiple electrode paddle lead is effective in trating intractable low back pain. Neuromodulation 4 (2) : 59-66

7. Cameron C (2004) Safety and efficacy of spinal cord stimulation for the treatment of chronic pain: a 20 year literature review. J Neurosurg (Spine 3) 100L254-100L267

8. Cherkin DC, Deyo RA, Loeser JD, Bush T, Waddell G (1994) An international comparison of back surgery rates. Spine 19: $1201-1206$

9. Dario A, Fortini G, Bertollo D, Bacuzzi A, Grizzetti C, Cuffari S (2001) Treatment of failed back surgery syndrome. Neuromodulation 4: 105-110

10. DePalma, Michael J, Jessica M Ketchum, and Thomas $R$ Saullo. Etiology of Chronic Low Back Pain in Pa tients
Having Undergone Lumbar Fusion. Pain Medicine (Malden, Mass.) (April 11, 2011).

11. Frey ME, Manchikanti L, Benyamine RM, et al. (2009) Spinal cord stimulation for patients with failed back surgery syndrome : a systematic review. Pain Physician 12 (2) :379397

12. Holsheimer J, Wesslink WA (1997) Effect of anode-cathode configuration on pararesthesia coverage in spinal cord stimulation. Neurosurgery 41 : 654-659 ; discussion 659660

13. Hoy D, Brroks, Blyth F, Buchbinder R (2010) The Epidemiology of low back pain. Best practice and research. Clinical Rheumatology 24 (6) : 769-781

14. Laurence Abeloos, Cristo Chaskis. " FBSS » et stimulation médullaire : résultats à long terme dans la littérature.Chirurgie de la douleur. Springer-Verlag Paris 2014 (133-147)

15. Long DM (1991) Failed back surgery syndrome. Neurosurg Clin Nv Am 2: 899-919

16. A. Levesque · S. Raoul · J.-P. Nguyen · J. Nizard. Subcutaneous Nerve Stimulation for the Treatment of Refractory Low Back Pain with Lumbar Neuropathic Component. Open-Label Study of 11 Patients and Review of the Literature. Douleur analg. (2015) 28:172-178. DOI 10.1007/s11724-015-0431-2.

17. North R, Shipley J, et al. (2007) ( North RB, Kidd D, Shipley J, Taylor RS (2007) Spinal Cord Stimulation versus reoperation for failed back surgery syndrome : a cost effectiveness and cost utility analysis based on a randomized, controlled trial.Neurosurgery 61(2):361 - 368 ; discussion 368-369

18. North R, Shipley J, et al. (2007) Practice Parameters for the Use od Spinal Cord Stimulation in the Treatment of Chronic Neuropathic Pain. Pain Med 8 Suppl 4 : S200-75

19. North RB, Kidd DH, Olin J, et al. (2006) Spinal Cord Stimulation for Axial Low Back Pain : A prospective Controlled Trial Comparing 16-Contact Insulated Electrodes With 4-Contact Percutaneous Electrodes : Comparison of SCS Electrodes for Low Back Pai. Neuromodulation Technol Neural Interface 9 :56-67

20. National medical management for neuropathic pain : Pain $132(1-2): 179-188$

21. Rigoard P, Jacques L, Delmotte A, et al. (2014) An Algorithmic Programming Approach for Back Pain Symptoms in Failed Back Syndrome Using Spinal Cord Stimulation with a Multicolumn Surgically Implanted Epidural Lead : A multicenter International Prospective Study. Pain Pract

22. Taylor RS, Desai MJ, Rigoard P, Taylor RJ (2013) Predictors of Pain Relief Following Spinal Cord Stimulation in Chronic Back ans Leg Pain and Failed Back Surgery Syndrome : A Systematic Review and Meta-Regression Analysis. Pain Pract doi :10.1111/papr.12095

23. Yong H. K. et al. (1980). Prevention of nerve root adhesions after laminectomy. Spine 5 (1): 59-6. 